\title{
Comparative Computational Study of Mechanical Behavior in Self-Expanding Femoropopliteal Stents
}

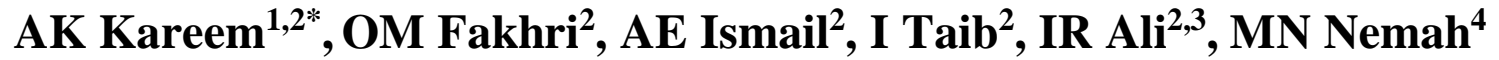 \\ ${ }^{1}$ Air Conditioning and Refrigeration Techniques Engineering Department, \\ Al-Mustaqbal University College, Babylon, 51002, IRAQ \\ ${ }^{2}$ Faculty of Mechanical and Manufacturing Engineering \\ Universiti Tun Hussein Onn Malaysia (UTHM) 86400 Parit Raja, Batu Pahat, Johor, MALAYSIA \\ ${ }^{3}$ Business Administration Department, Al-Mustaqbal University College, Babylon, IRAQ \\ ${ }^{4}$ Engineering Technical College-Najaf, Al-Furat Al-Awsat Technical University, 32001, Najaf, IRAQ \\ *Corresponding Author
}

DOI: https://doi.org/10.30880/ijie.2020.12.01.021

Received 25 November 2019; Accepted 29 December 2019; Available online 30 January 2020

\begin{abstract}
The use of the stent to treat peripheral artery disease (PAD) is increased and the proportion of failures also increases. The femoropopliteal artery (FPA) experiences a high deformation ratio compared to the cardiovascular artery due to limp flexion and daily activities that could lead to stent failure, as well as increasing the number of observed mortality and morbidity. In the present work, two of the common PAD stent design models represented as STENT I and STENT II were analyzed by using of finite element method (FEM) to simulate the most mechanical loading modes that could occur in FPA, such as axial tension and compression, torsion, three-point bending and radial compression to give a good understanding of deformation that affected stent inside the in-vivo. The gradual force load was used to simulate all modes, the force values are $0.25 \mathrm{~N}, 0.5 \mathrm{~N}, 1.5 \mathrm{~N}, 2.5 \mathrm{~N}, 3.5 \mathrm{~N}$ and $5.5 \mathrm{~N}$ until the stent models obtain the yield-point. The comparison of stent models (STENT I, STENT II) was performed in terms of graphs of total deformation, force-stress and stress-strain for all test modes. The similarity ratio of the total deformation in axial tension and the compression mode for STENT I and STENT II was $17 \%$ and that may indicate that STENT I obtained a high deformation value instead of STENT II, while, the torsion similarity ratio was $86 \%$ which could show a good agreement in this mode, as well as the similarity ratio, was $78 \%$ of the total three-point bending deformation and the value of the similarity ratio in the radial compression mode was $23 \%$. Still unclear what is the clinical mode of mechanical deformation that is more important than others with changing the length of the lesion and stent diameter, and the fatigue life test provides a better understanding of the mechanical tests that must be sought.
\end{abstract}

Keywords: Peripheral artery diseases, femoropopliteal, stent design, finite element method, mechanical loads

\section{Introduction}

Diseases of the clogged vascular arteries are one of the most common diseases that affect blood flow within the human body because many reasons lead to reduced streaming of blood flow, such as inflammatory and physiological obstacles that could lead to normal neointimal-hyperplasia [1]. This type of disease becomes the majority of peripheral artery diseases (PAD) that also affected the blood flow of the extremities, however, the increasing number of patients worldwide, such as that affecting the femoropopliteal artery (FP), leads to an increase in morbidity and mortality numbers, around 200 million patients with PAD [2]. There are many ways to treat the FPA such as medical-therapy, 
endovasculartherapy, and open-surgical treatment [3]-[5], A small mesh device (stent) used to treat PAD is a good option, in addition to being good outcomes and a permanent choice as well.

Although, the superelastic properties of Nitinol (nickel and titanium) [6], [7] that are used to produce self-expanding stents for use in the treatment of PAD, mechanical obstacles appeared with varying configurations. Many of stent design characteristics are required to agree with FPA environment [8], as well as the limb flexion [9] leads to different of mechanical deformation that could take into account to keep artery lumen open. However, the mechanical characteristics that are required in the FPA stent such as maintaining axial tension and compression, torsion and bending with low resistance that gives stent models more flexibility to deform with variable FPA activities, as well as the radial compression safer to keep the stent open, as much as necessary to evaluate the fatigue life of the stent design and that required a special environment, a large number of patients, several stent samples and a long time [10]-[12]. Further, the mechanical performance of common stent design models was investigated in the workbench with different modes to provide a better understanding of the stent configuration inside in-vivo[13], [14].

The computational study of finite element method (FEM) helps researchers to simulate the behavior of stent models within the artery in-vivo, as well as reduce time and cost, as well as to improve the stent design. The comparison of mechanical fatigue life under axial tension/compression, torsion, three-point bending and radial compression [15], and the mechanical performance was measured to improve the stent design [16], [17]. In this work, the computational of FEM was analyzed (using SOLIDWORK 2016 to draw the models, then exported to ANSYS 19.0 for analysis) for two of the common stent designs used to treat the FP artery (SMART Control and Complete SE) presented as STENT I and STENT II, the use of gradual mechanical forces was applied to evaluate each of the axial tension / compression, torsion, threepoint bending and radial compression.

\section{Materials and Methods}

Two of the common FPA stents have been tested using the finite element method (FEM) in terms of mechanical performance by applying several of gradual-loads in different stent designs. In special, the cyclic loads were performed in mechanical tests under axial tension, axial compression, three-point flexion, torsion, and radial compression. In this work, two different Nitinol self-expanding stents called STENT I and STENT II were used, which resemble the Smart Control (Cordis) and Complete SE (Medtronic) commercial stents, respectively. The commercial code of the ANSYS WORKBENCH 19.0 software (Inc., Canonsburg, PA, USA) has been used for the numerical analysis.

\subsection{Stent models}

The three-dimensional geometries of the stents were modeled with the help of the commercial software SOLIDWORKS 2016 (Dassault Systèmes SolidWorks Corporation, United States) by reassembling the real dimen sions of the commercial stents imitating the stents sought in the researches [18], [19] and reconstructed them as shown in Figure 1(a) and (b) with their connections. Both models of stents have a length of $40 \mathrm{~mm}$ and $7 \mathrm{~mm}$ in diameter and the thickness of both models is $0.2 \mathrm{~mm}$, taking into account recent research [20], as well as the number of struts around the circumference of the ring is 36 and 34 for STENT I and STENT II, respectively, and the number of rings in the longitudinal direction is 18 for both. Table 1 and Figure 2 show the detailed dimensions in brief detail of the zigzag design of the stent models and the open cell stent models in this study with peak-to-valley in STENT I and peak-to-peak in STENT II. Alloys with shape-memory and the super-elastic behavior of Nitinol properties [21], [22] are used for both stent models with a temperature of $37^{\circ} \mathrm{C}$ and the final surface was ignored for both stent models as summarized in Table 2 .

Table 1 - Details of stent dimensions

\begin{tabular}{|c|c|c|c|c|c|c|c|c|c|}
\hline 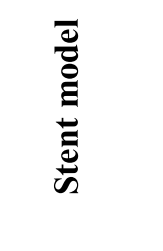 & 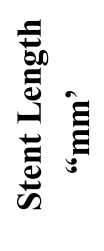 & 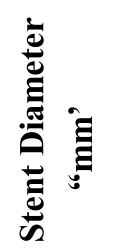 & 崖 & 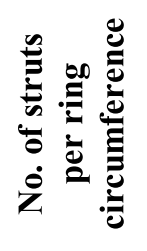 & 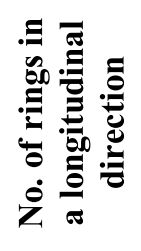 & 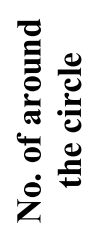 & 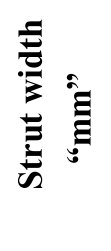 & 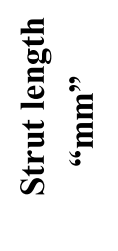 & : \\
\hline STENT I & 40 & 7 & 0.2 & 36 & 18 & 6 & 0.13 & 1.99 & 27.01 \\
\hline STENT II & 40 & 7 & 0.2 & 34 & 18 & 6 & 0.2 & 1.79 & 44.80 \\
\hline
\end{tabular}

Three of the SOLIDWORK models are generated to cover all types of tests. The first model for each of the axial tension / compression and torsion tests consists of the stent body with two-handle brackets with an internal diameter of 
$7.3 \mathrm{~mm}$ and $7.5 \mathrm{~mm}$ for the external diameter located at $5 \mathrm{~mm}$ away from each edge to address the experimental study that in the literature review [14], as well as to reduce the edge effect. In the second model, the three-point bending consisting of the body of the stent and two supports with a diameter of $3 \mathrm{~mm}$ located $5 \mathrm{~mm}$ from the edge is presented and the third model simulates that the radial compression consists of the body of the stent with the base and rectangular mobile plate along the body of the stent as illustrated in Figure 3 (a, b, c, and d).

(a)
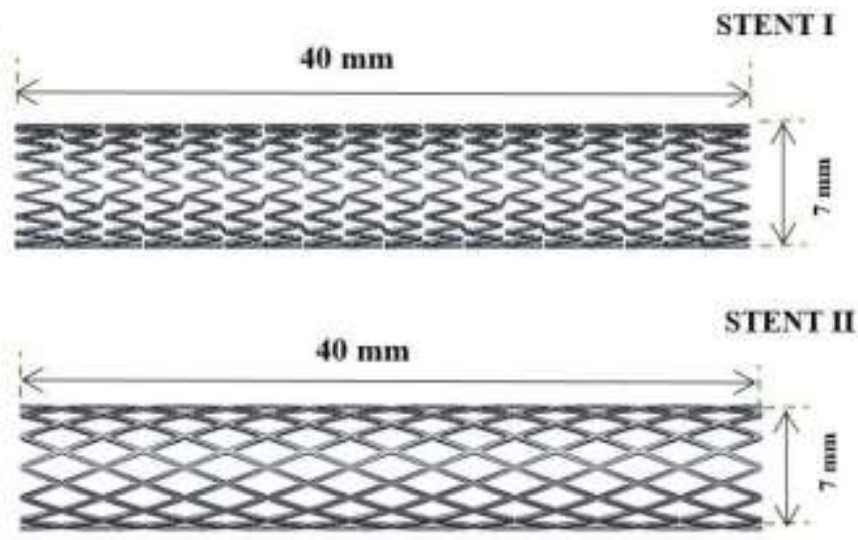

(b)

Peak-to-Valley

STENT I

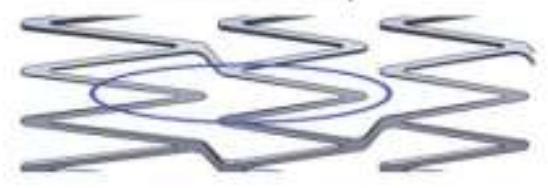

Peak-to-Peak

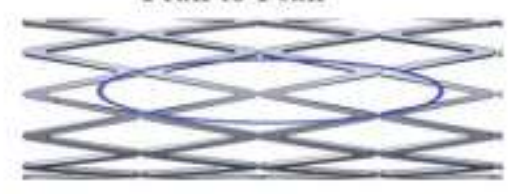

STENT II

Fig. 1 - (a) STENT I and STENT II dimensions; (b) the different connections types

Table 2 - Nitinol properties

\begin{tabular}{|c|c|c|}
\hline No. & Characteristics name & Values \\
\hline 1. & Austenite Young's modulus & $35877 \mathrm{MPa}$ \\
\hline 2. & Austenite Poisson's ratio & 0.33 \\
\hline 3. & Martensite Young's modulus & $24462 \mathrm{MPa}$ \\
\hline 4. & Martensite Poisson's ratio & 0.33 \\
\hline 5. & Transformation strain & 0.0555 \\
\hline 6. & Loading start of transformation stress & $489 \mathrm{MPa}$ \\
\hline 7. & Loading end of transformation stress & $572 \mathrm{MPa}$ \\
\hline 8. & Temperature & $37^{\circ} \mathrm{C}$ \\
\hline 9. & Unloading start of transformation stress & $230 \mathrm{MPa}$ \\
\hline 10. & Unloading end of transformation stress & $147 \mathrm{MPa}$ \\
\hline 11. & Density & $6.5 \mathrm{~g} / \mathrm{cm}^{3}$ \\
\hline
\end{tabular}

The stent models are discretized using the order of meshing in ANSYS 19.0, therefore, to obtain a more suitable sensitive mesh, the tetrahedrons method with quadratic order element as in previous studies [23], [24], as well as, for each center of relevance and center of angle of amplitude, a fine size is used and for statistics the information are 270688 , 125267 in STNET I and 220448,106307 in STENT II for nodes and elements, respectively. As shown in Figure 3 (e) and (f). 
(a) STENT I

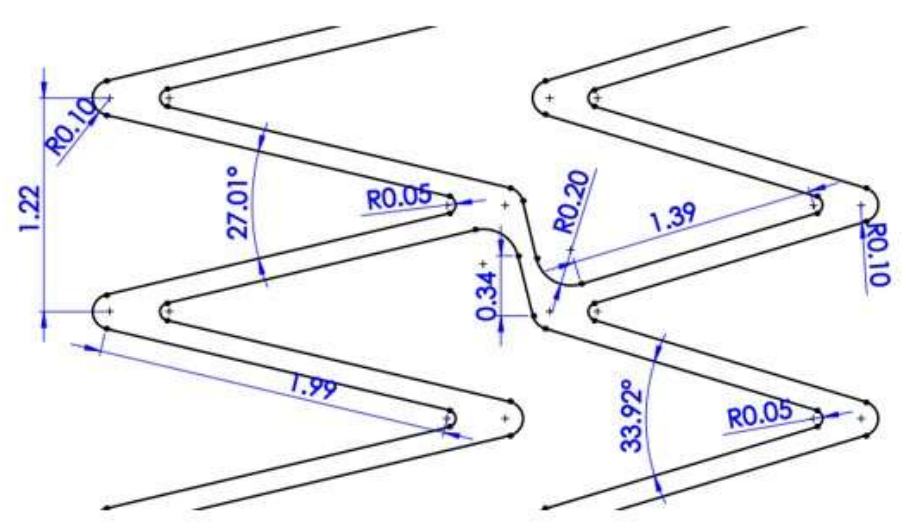

(b)

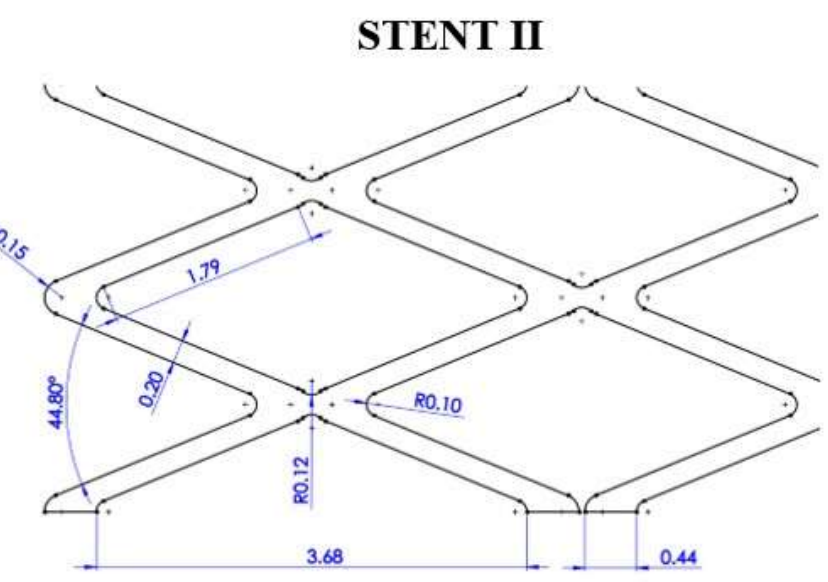

Fig. 2 - Details of the dimensions of the stent models: (a) STENT I, and (b) STENT II

\subsection{Computational testing scenario}

The analysis of the comparative simulation of the mechanical performance of the stents was performed after designing the stent model in SOLIDWORK 2016 by inserting the models into the ANSYS 19.0 software. After that, the test sequence for both stents was performed as axial tension, axial compression, torsion, three-point bending and radial compression with a mechanical test temperature of $37^{\circ}$. The axial tension and compression have been tested simulating the experimental work done in the literature [14] as shown in Figure 3 (a) supporting the stent body through cylindrical rings $5 \mathrm{~mm}$ away from the edges to reduce the effect of the edges as to give simulation close to the experimental. One of the cylindrical supports moved axially to stretch the stents in the tension test under values of gradual loads of $0.25 \mathrm{~N}, 0.5$ $\mathrm{N}, 1 \mathrm{~N}, 1.5 \mathrm{~N}, 2.5 \mathrm{~N}, 3.5 \mathrm{~N}$ and $5.5 \mathrm{~N}$, until reach yield point.

The torsion test was carried out by fixing one of the cylindrical supports and the other support moment force was applied to rotate the stents clockwise with gradual moments of 0.25 N.mm, 0.5 N.mm, 1 N.mm, 1.5 N.mm, 2.5 N.mm, 3.5 N.mm, 5.5 N.mm, 8.5 N.mm and 11.5 N.mm until the moment force reached for yield point for the stents models as shown in Figure 3 (b). The three-point bending test was performed by horizontally supporting the stent body with two cylindrical rods ( $3 \mathrm{~mm}$ diameter) $5 \mathrm{~mm}$ away from the edges, and at the midpoint of the stent the vertical gradual loads of $0.25 \mathrm{~N}, 0.5 \mathrm{~N}, 1 \mathrm{~N}, 1.5 \mathrm{~N}, 2.5 \mathrm{~N}$ and $3.5 \mathrm{~N}$ applied until the stent fails as illustrated in Figure 3 (c). And, the last test was that radial compression was achieved through the fixed support of the stents by the horizontal rectangular plate ( 8 $\mathrm{mm}$ wide and $3 \mathrm{~mm}$ thick) along the length of the stent, as well as the application of vertical gradual loads of $0.25 \mathrm{~N}, 0.5$ $\mathrm{N}, 1 \mathrm{~N}, 1.5 \mathrm{~N}, 2.5 \mathrm{~N}, 3.5 \mathrm{~N}, 5.5 \mathrm{~N}, 8.5 \mathrm{~N}, 11.5 \mathrm{~N} 14.5 \mathrm{~N}$ and 17.5 through the radial plate applied on top of the stent surface vertically as illustrated in Figure $3(\mathrm{~d})$. 
(a)

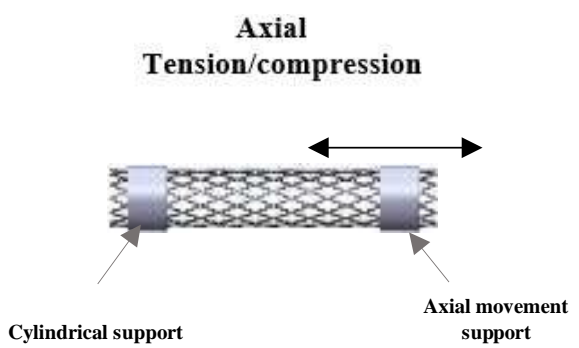

(c)

Three Point-Bending

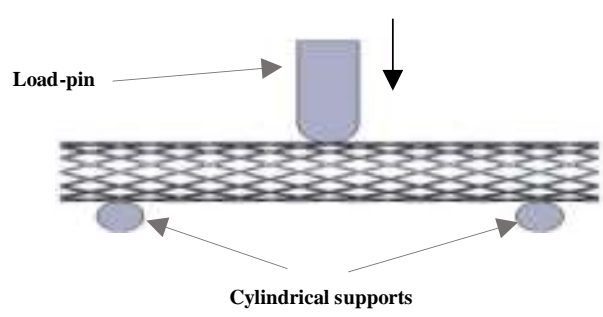

(e)

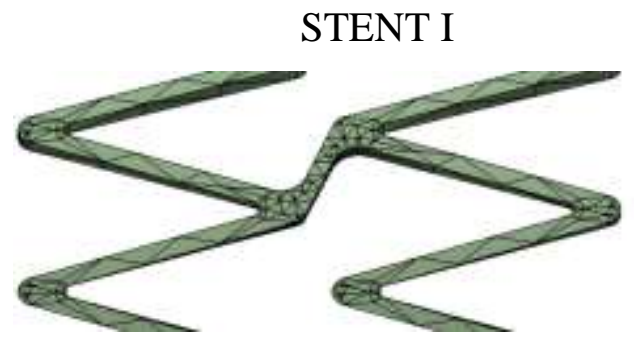

(b) Torsion

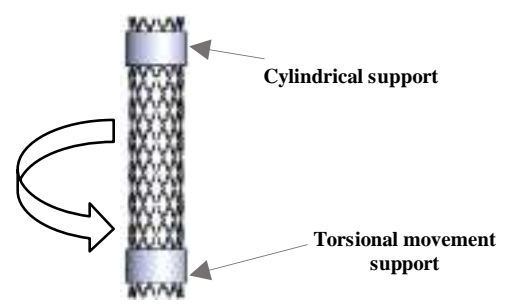

(d)

Radial compression

Rectangular mobile plate

(f)

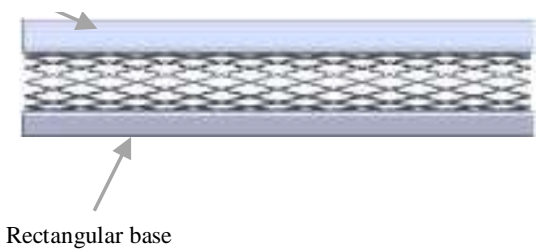

STENT II

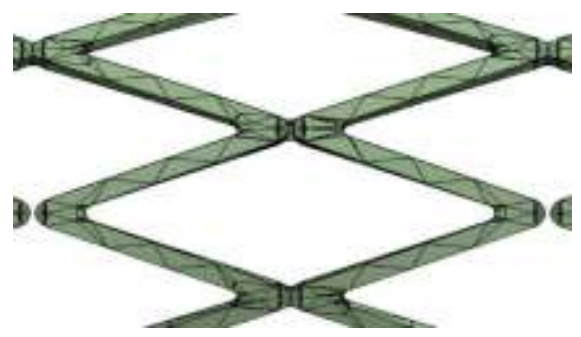

Fig. 3 - Shows the stent models (a) under axial tension/compression; (b) under torsion; (c) under three-point bending, (d) radial compression, (e) meshing of STENTI; (f) meshing of STENT II

\section{Results}

\subsection{Validation of stent models}

The validation step is one of the most important to verify the computational models, as well as to have more confidence that the model is enough for existing models. However, Figure 4 (a, b) shows the validation of stent models with experimental work [14] under axial tension/compression loads. The Force-Strain diagram was choosing to compare the behavior of the Complete SE model under axial tensionlcompression loads. Good agreement was observed with the existing model with an error ratio of $\sim 2 \%$ that provides a good indicator and is approved with other tests (three-point flexion, torsion, and radial compression).

(a)

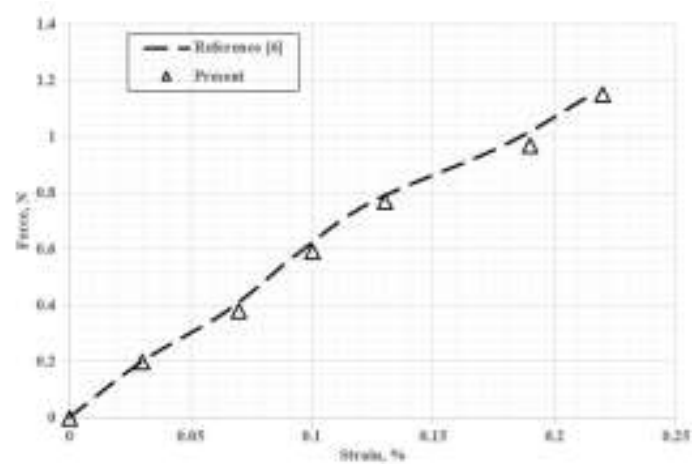

(b)

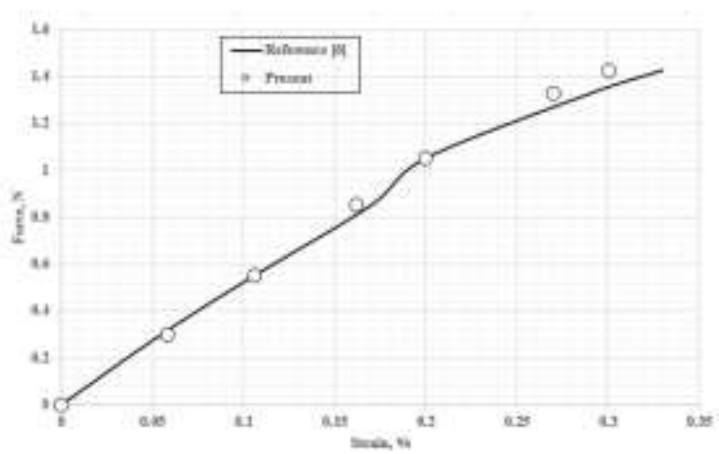

Fig. 4 - Stent models validation under: (a) axial tension; (b) axial compression loads with force-strain diagram 


\subsection{Under axial tension and compression loads}

The axial tension results show the variation values between both stent models (STENT I, STENT II) with the application of the same force values. The total deformation for the stent models shows a demonstration of STENT II at $0.25 \mathrm{~N}$ with $0.129 \mathrm{~mm}$ and $0.094 \mathrm{~mm}$ for STENT I and STENT II, respectively. The deformation for both stents increases with increasing force values. Up to $5.5 \mathrm{~N}$, the yield point behavior was observed for STENT I with $13.49 \mathrm{~mm}$, but in STENT II it was $2.31 \mathrm{~mm}$, and this pattern behavior demonstrates the same results that were observed in experimental research [14], as plotted in Figure 5.

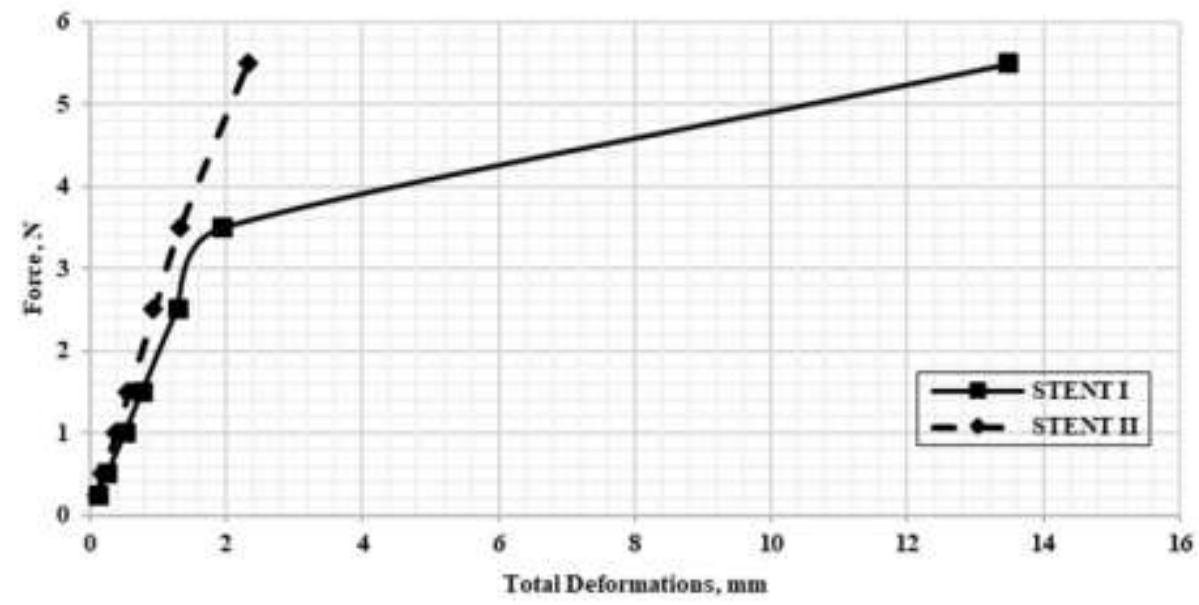

Fig. 5 - Total deformation for STENT I and STENT II under axial tension force

However, the von Mises stress outcomes of stent models at $0.25 \mathrm{~N}$ were 44.72 Mpa and 36.26 Mpa for STENT I and STENT II, respectively. The increase in force values also leads to an increase in stress values, but the first of the three values gradually increased twice for both models, until, in the fourth value at $1.5 \mathrm{~N}$, the magnitude of the stresses it was 268.31 Mpa and 217.6 for STENT I and STENT II, respectively, and the double-double increase observed for STENT I in fifth value at $2.5 \mathrm{~N}$ was 406.31Mpa and a gradual increase of 362.66 Mpa was observed for STENT II. At 5.5 N, the stress value was 851.54 Mpa for STENT I, while in the case of STENT II it was 507.44 Mpa as shown in Figure 6 (a).

(a)

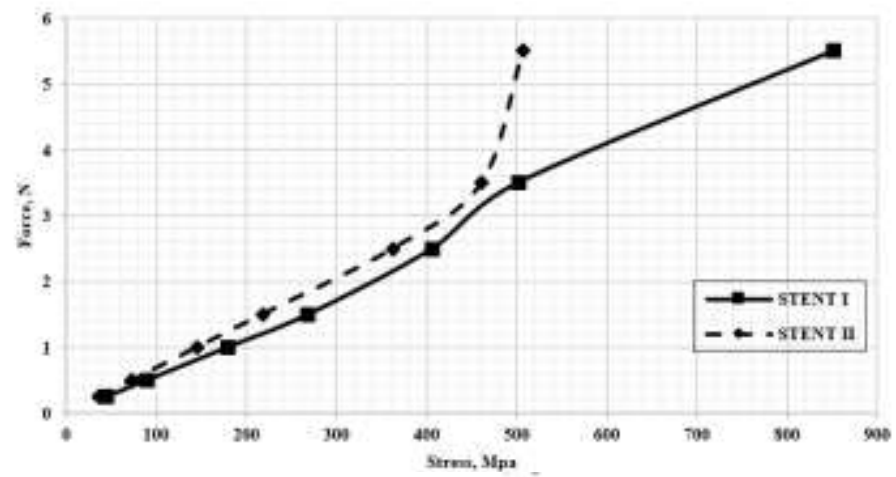

(b)

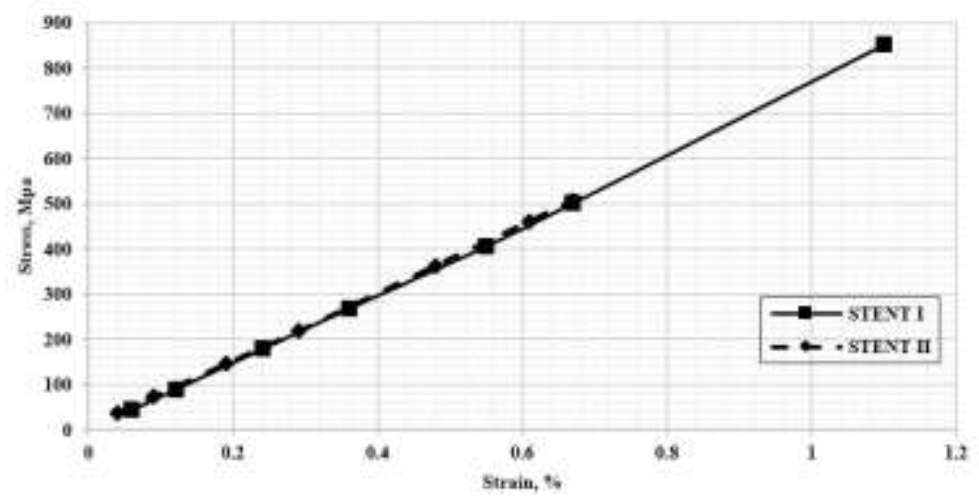

Fig. 6 - Axial loads for Stent models behavior of: (a) force versus stress; (b) stress and strain response

The von Mises deformation values generated from the forces applied in the stent models are also different, at 0.25 $\mathrm{N}$ the strain values are 0.06 and $0.04 \%$ for STENT I and STENT II, respectively. The observed strain behavior gradually increases with the increase in the magnitude of the force, and, at $5.5 \mathrm{~N}$, the deformation is 1.1 and $0.67 \%$ for STENT I 
and STENT II, respectively, which could explain the linear relationship between the stress and strain values, as shown in Figure 6 (b). Moreover, Figure 7 (a) presents the comparative in changing of stent structures during applying the gradual force in axial tension. The values of total deformation in axial compression are almost the same values of axial tension, except that at $5.5 \mathrm{~N}$ the axial compression value was less than the tension close to $11 \%$ and $1 \%$ for STENT I and STENT II, respectively as shown in Figure 8. While the different stress of von Mises in STENT I starts at $2.5 \mathrm{~N}$ (406.31 Mpa of tension, 405.18 Mpa of compression) while for STENT II the different stress observed at $3.5 \mathrm{~N}$ was greater than in tension (461.3 Mpa of tension, $462 \mathrm{Mpa}$ compression) but returned to normal behavior at $5.5 \mathrm{~N}$ less than tension (507.44 Mpa tension, 500.79 Mpa compression), Figure 7 (b) shows changing of stent models structure under axial compression.

(a)

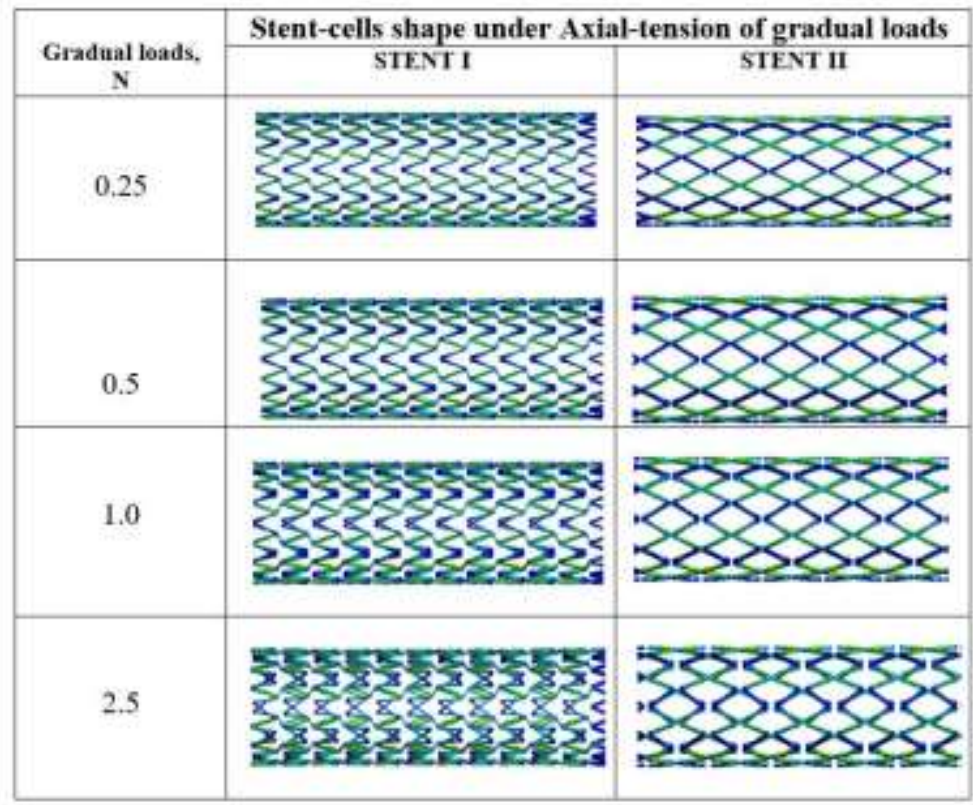

(b)

\begin{tabular}{|l|l|l|}
\hline \multirow{2}{*}{$\begin{array}{l}\text { Gradual } \\
\text { loads, } \mathrm{N}\end{array}$} & \multicolumn{2}{|c|}{ Stent-cells shape under Axial-compression of gradual loads } \\
\cline { 2 - 3 } & STENT I \\
\hline 0.25 & & \\
\hline 1.0 & &
\end{tabular}

Fig. 7 - The changing of stent structure during increasing force: (a) under axial tension, and (b) under axial compression 


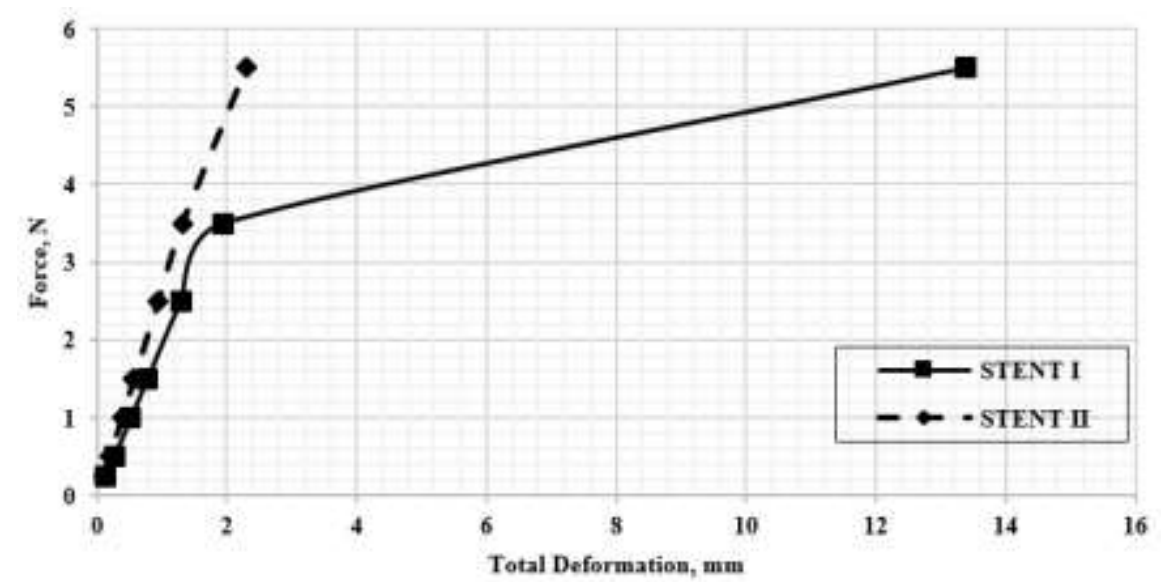

Fig. 8 - Total deformation for STENT I and STENT II under axial compression force

\subsection{Under torsion loads}

The values of results of the stent models in gradual moments in the sense of clockwise to present the torsion in ANSYS 19.0 software were approved in good behavior with the experimental study [14]. The moment values were gradually increased until the stent deformation edge was obtained for both stent models (STENT I, STENT II). The results for the total deformation at $0.25 \mathrm{~N} . \mathrm{mm}$ are $0.055 \mathrm{~mm}$ and 0.029 for STENT I and STENT II, respectively, so clear to observe the difference in deformation (up to double) between STENT I and STENT II. However, the gradual moment values increase as well as the deformation values as plotted in Figure 8. The deformation behavior in STENT I was increasing in fixed values from $0.25 \mathrm{~N} . \mathrm{mm}$ to $3.5 \mathrm{~N} . \mathrm{mm}$, but the increasing magnitude increased significantly to 5.5 N.mm to be $1.206 \mathrm{~mm}$, while at the same time $(5.5 \mathrm{~N} . \mathrm{mm})$ the behavior of STENT II was gradually increasing, until the value of the moment reached $11.5 \mathrm{~N} . \mathrm{mm}$ (more than in STENT I) the STENT II deformed with $1.339 \mathrm{~mm}$ as shown on Figure 9.

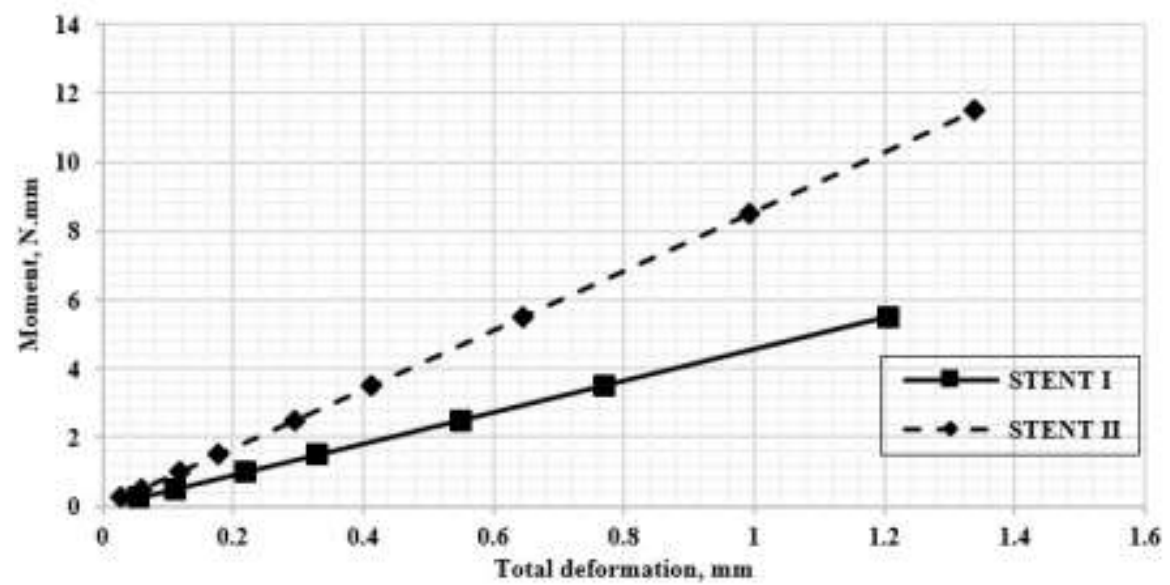

Fig. 9 - Total deformation under gradual moment for STENT I and STENT II

In addition, the von Mises stress results at 0.25 N.mm are 14.29 Mpa and 10.67 Mpa for STENT I and STENT II, respectively. Figure 10 (a) summarizes the gradual moment with stress values, also, the increase in momentum leads to an increase in the magnitude of the stress as well. However, the increment of the gradual moment keeps the stress increase constant for both models, reaching $5.5 \mathrm{~N} . \mathrm{mm}$ and $11.5 \mathrm{~N} . \mathrm{mm}$ from the moment the stress values become equal to 315 Mpa and $437.73 \mathrm{Mpa}$ for STENT I and STENT II, respectively. 
(a)

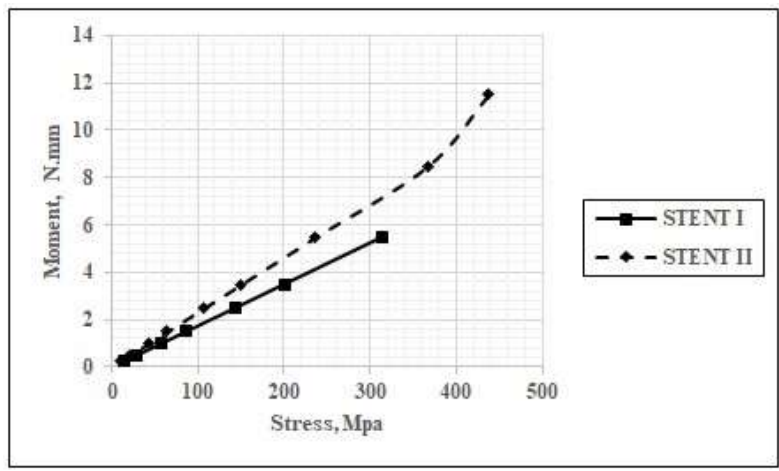

(b)

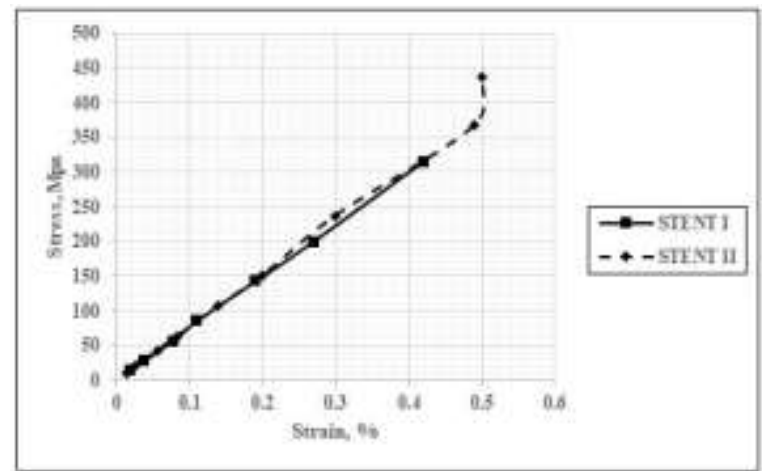

Fig. 10 - Shown: (a) moment with von Mises stress for both STENT I and STENT II models; (b) stress and strain relationship

The von Mises stress versus von Mises strain as illustrated in Figure 10 (b) shows the semi-linear behavior and close enough to observe the similarity between them, but this behavior changed slightly when the STENT I deformed at 5.5 N.mm with strain value of $0.42 \%$, while STENT II withstand up to $11.5 \mathrm{~N} . \mathrm{mm}$ at the moment with $0.5 \%$ strain, and this behavior gives advantage to the STENT II model. More understanding of the behavior for both stent models under the torsion test Figure 11 summarizes the changing in the structure of stent models during gradual moments.

\begin{tabular}{|c|c|c|}
\hline Gradual loads, N & Stent-cells shape under torsion loads \\
\cline { 2 - 3 } & STENT I & STENT II \\
\hline \multirow{3}{*}{0.25} & & \\
\hline & & \\
\hline & & \\
\hline & & \\
\hline & & \\
\hline & & \\
& & \\
& & \\
& & \\
\hline & & \\
\hline
\end{tabular}

Fig. 11 - Changing of stent structure under gradual moment

\subsection{Under three-point bending loads}

Three-point bending test performed with a minimum of $0.25 \mathrm{~N}$ and a maximum of $2.5 \mathrm{~N}$ of gradual forces for STENT I until the failure occurs in the stent, while in STENT II the gradual force values are $0.25 \mathrm{~N}$ minimum and 3.5 Maximum $\mathrm{N}$ until the failure in the stent structure occurs. The plotted values of force and total deformation are summarized in Figure 12. The variable of gradual forces produces different values of deformations, such as, at $0.25 \mathrm{~N}$, the values of total deformation were $0.42 \mathrm{~mm}$ and $0.26 \mathrm{~mm}$ for STENT I and STENT II, respectively. The gradual increase in deformation was constant (almost double) for STENT I at $0.25 \mathrm{~N}, 0.5 \mathrm{~N}, 1 \mathrm{~N}$ and $1.5 \mathrm{~N}$ were $0.42 \mathrm{~mm}, 0.82 \mathrm{~mm}, 1.65 \mathrm{~mm}$ and 2.63 $\mathrm{mm}$, respectively, suddenly the deformation value becomes $8.47 \mathrm{~mm}$ at a force of $2.5 \mathrm{~N}$ that observed the behavior of plasticity at this magnitude of force, while STENT II performed the same behavior of STENT I, but the deformation occurred at $3.5 \mathrm{~N}$ of force with $6.69 \mathrm{~mm}$ as shown in Figure 12. 


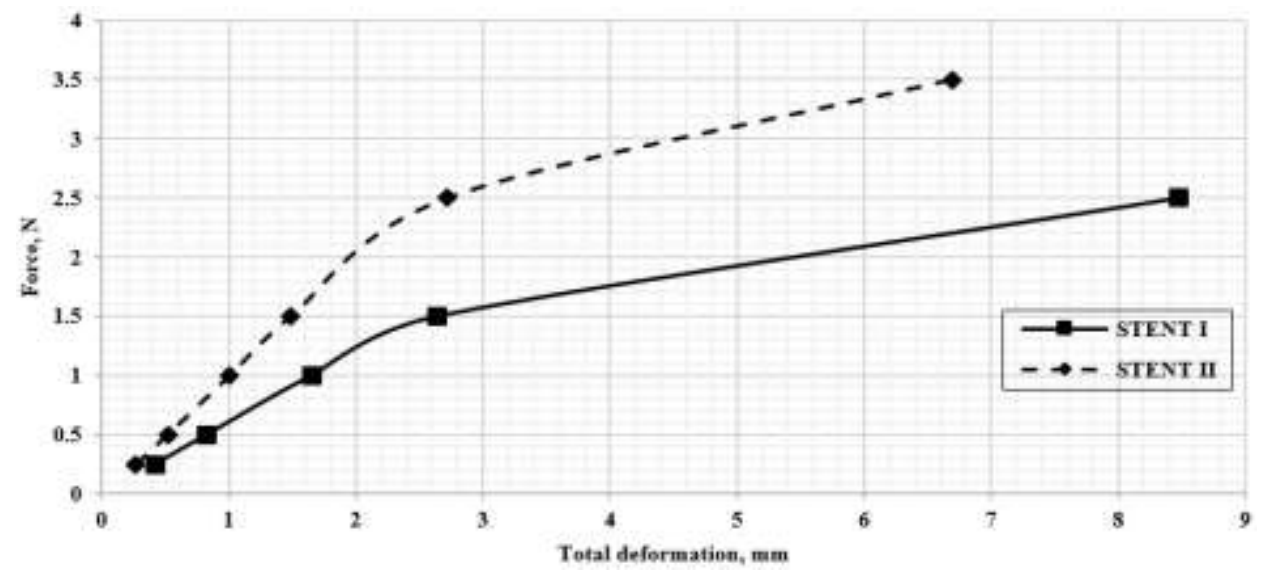

Fig. 12 - Force versus total deformation behavior of three-point bending for both stent models

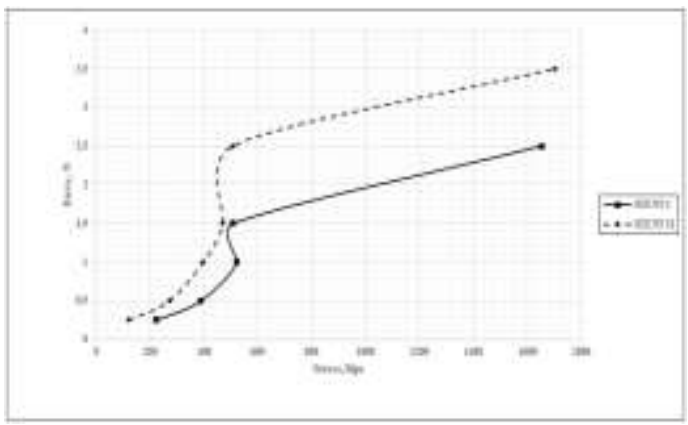

(a)

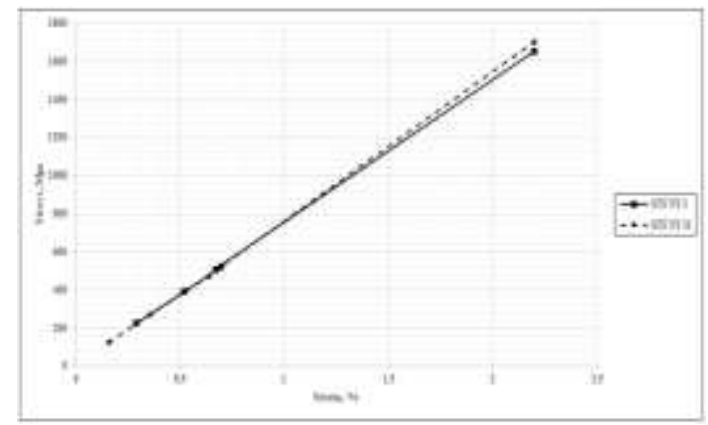

(b)

Fig. 13 - Three-point bending of: (a) force versus stress for both stent models, and (b) stress and strain behavior for both models

In addition, von Mises stress values at $0.25 \mathrm{~N}$ were 224.01 Mpa and 122.85 Mpa for STENT I and STENT II, respectively. The change in stress values was not linear during the increase of the gradual forces as illustrated in Figure 13 (a), but the stress and strain are in linear change as shown in Figure 13 (b). The stress value at $2.5 \mathrm{~N}$ was the plasticity behavior with a value equal to $1653.3 \mathrm{Mpa}$ in STENT I, as well as, in the case of STENT II, the plasticity behavior observed at $3.5 \mathrm{~N}$ with $1703.3 \mathrm{Mpa}$ as shown above. The observation changing in stents models structure during threepoint bending were illustrated in Figure 14.

\subsection{Under radial compression loads}

The radial compression test was performed by applying the radial force gradually, such as the minimum force was $0.25 \mathrm{~N}$ for both stent models, but the maximum force values were $11.5 \mathrm{~N}$ and $17.5 \mathrm{~N}$ for STENT I and STENT II, respectively. The total deformation at $0.25 \mathrm{~N}$ was $0.06 \mathrm{~mm}$ for STENT I and $0.02 \mathrm{~mm}$ for STENT II, however, the gradual increase in deformation was regular and somewhat constant for both models, such as $0.5 \mathrm{~N}, 1 \mathrm{~N}, 1.5 \mathrm{~N}$ and 2.5 were 0.13 $\mathrm{mm}, 0.25 \mathrm{~mm}, 0.38 \mathrm{~mm}$ and $0.85 \mathrm{~mm}$ for STENT I, respectively, until at $11.5 \mathrm{~N}$ the fault for STENT I occurs with 8.641 $\mathrm{mm}$, while, in the case of STENT II, it increases gradually too, but the deformation failure occurs at $17.5 \mathrm{~N}$ with 2.01 $\mathrm{mm}$ as shown in Figure 15.

The change in von Mises stress values was gradually doubled for both stent models, for example, with STENT I at $0.25 \mathrm{~N}, 0.5 \mathrm{~N}, 1 \mathrm{~N}$ were 48.19 Mpa, 96.84 Mpa and 195.51 Mpa, until deformation was obtained at $11.5 \mathrm{~N}$ with deformation plasticity with $3533.6 \mathrm{Mpa}$, in the case of STENT II, the increase in stress values was the same in STENT I but the deformation occurred at 17.5 N with 518.02 Mpa as illustrated in Figure 16 (a), and (b) shows the stress and strain relationship in the radial compression for both stent models. Forefather, the gradual changing of cross section for both models give clear understanding of radial force effects as shown in Figure 17. 


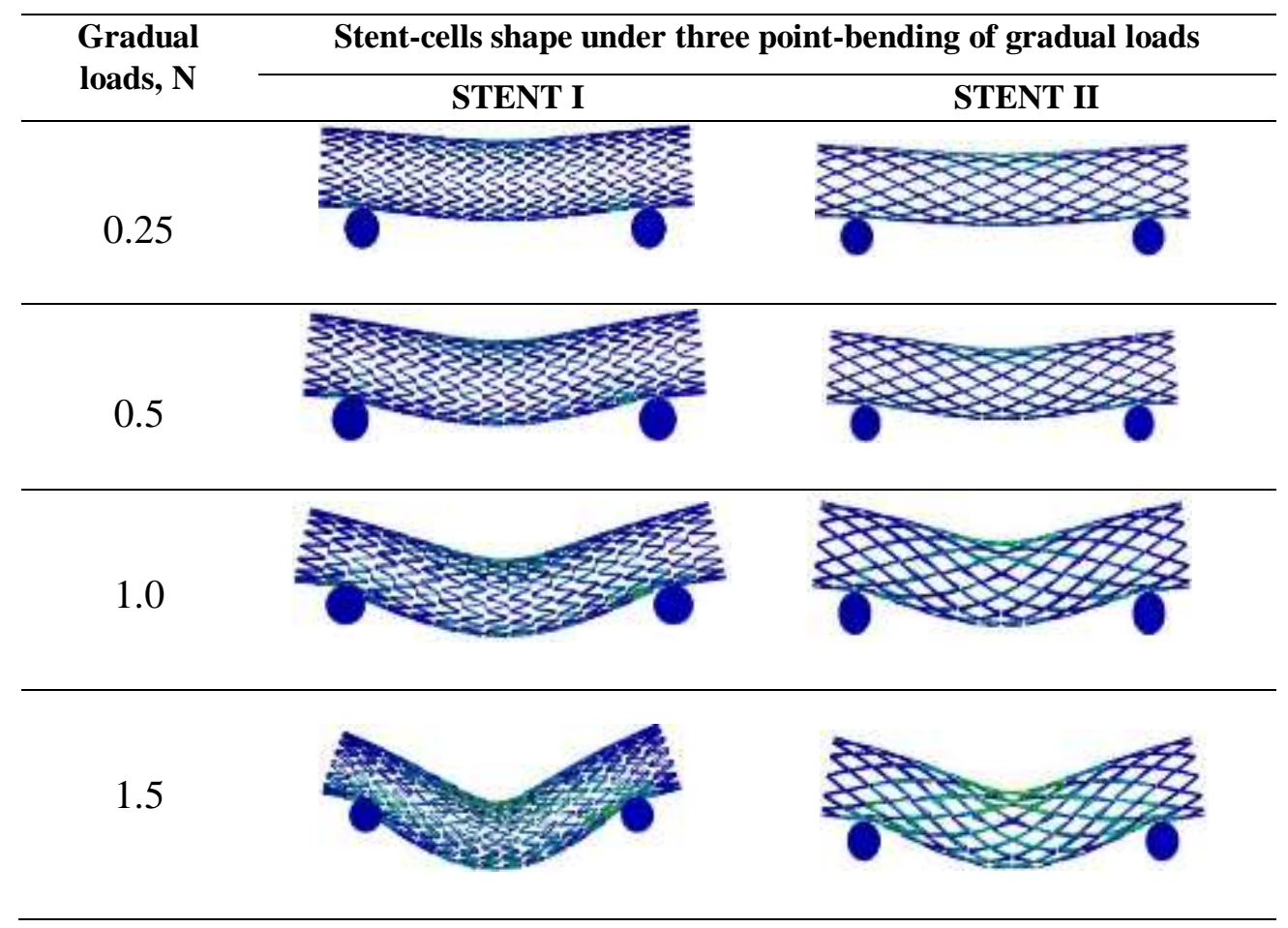

Fig. 14 - Three-point bending effects for both stent models

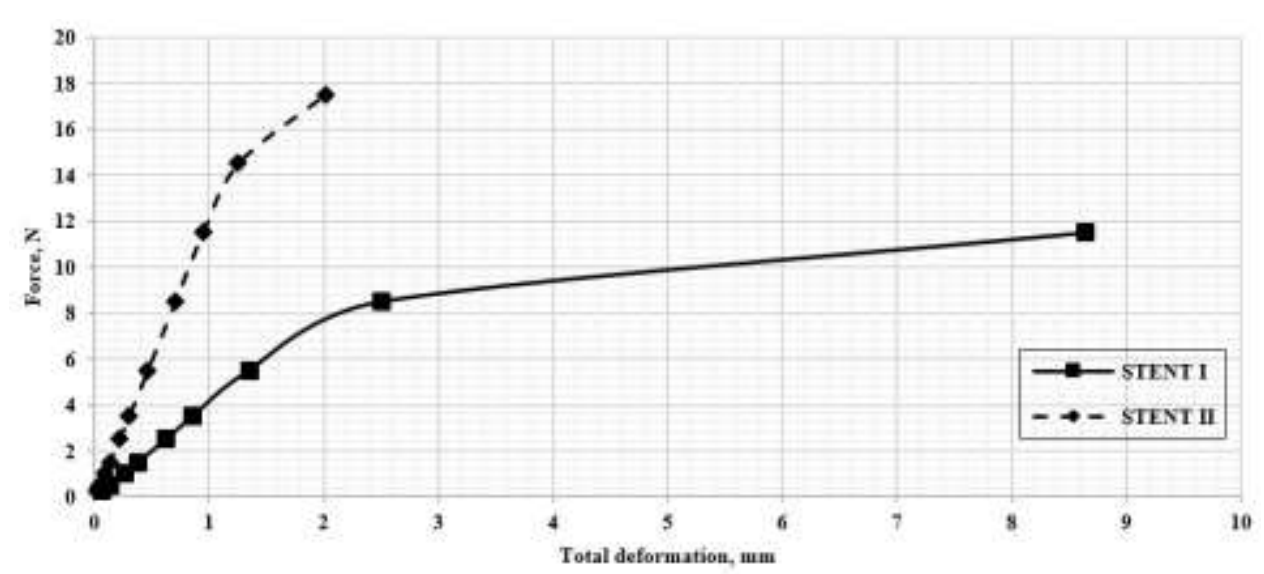

Fig. 15 - Force versus total deformation behavior of radial compression for both stent models

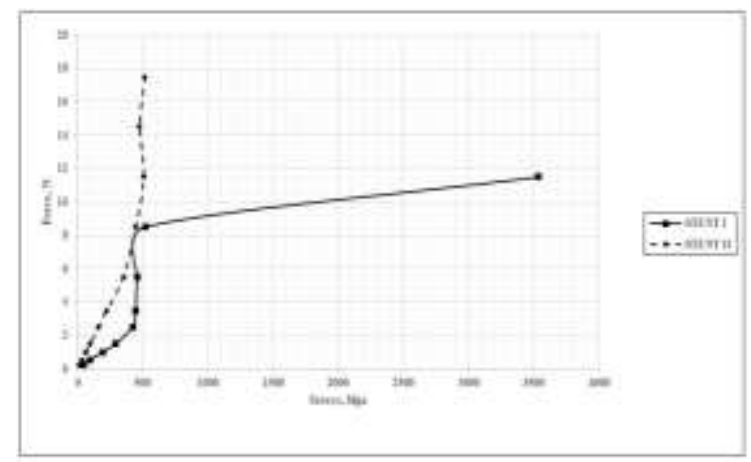

(a)

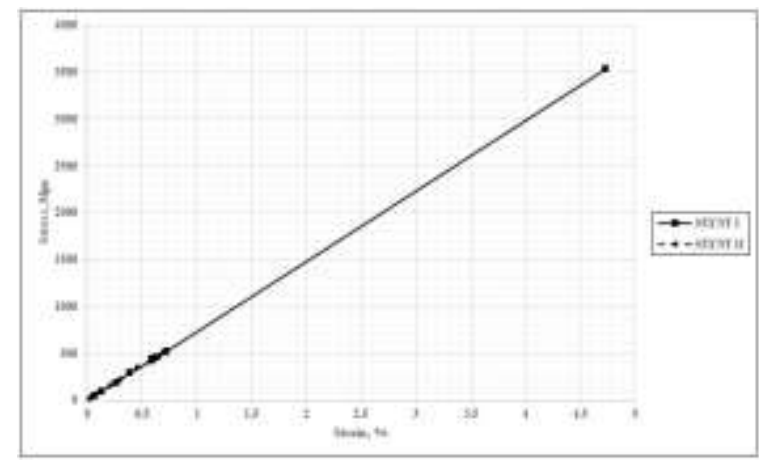

(b)

Fig. 16 - Radial-compression of (a) force versus stress for both stent models, and (b) stress and strain behavior for both models 


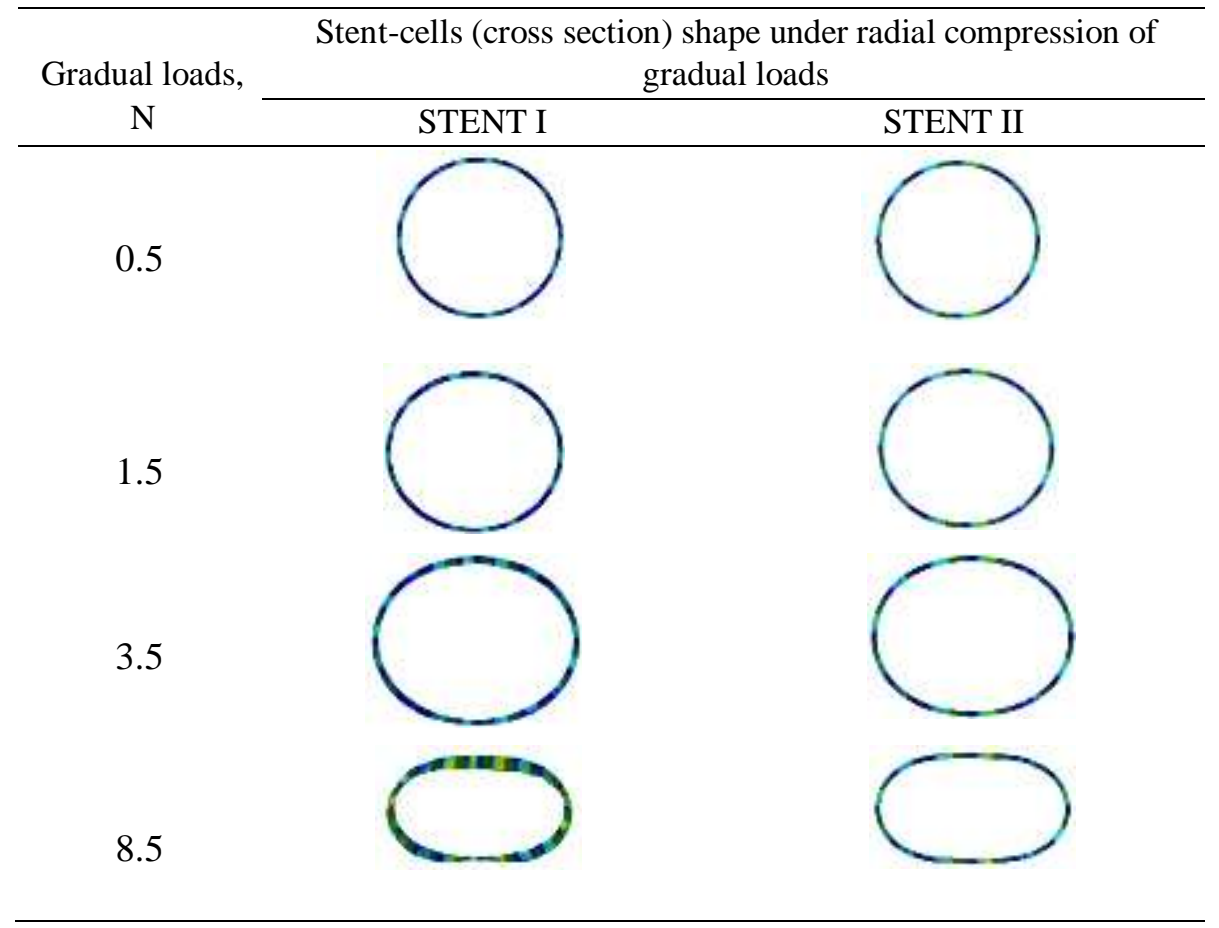

Fig. 17 - Radial force effects on cross section for both stent models

\section{Discussions}

The change in the mechanical environment occurs in the FP artery due to artery movement and daily activities that could lead to a high failure rate compared to other arteries [8], [19], [25]. The most common mechanical loads in FPA are axial loads (tension and compressions), torsion, bending, and radial compression. The two common models of FP stents (STENT I and STENT II) were compared under various mechanical modes with gradual forces in till to reach yield limit. Yet, during the insertion of a stent model into the limb and the straight FPA situation that leads to a pre-stretched FPA [26] configuration could lead to many modes of mechanical loading. Moreover, in daily activities, such as the limb in the flexion configuration, the FPA stents obtained axial tension and, in the guardian state, the severe FPA stents of an acute axial compression approximately $39 \%$ of the stent length [9], [27]. The most different among the coronary stents of the balloon-expandable models made of cobalt-chromium or stainless-steel and the FP stents (Nitinol) of the selfexpanding models is that the FP stent models must take many deformations with the artery, that would ensure reducing the arterial injury, while the actions are not necessary for the coronary artery.

Under axial tension and compression of gradual loads, STENT II showed the good results compared to STENT I, just as the stent model cells deform with different behavior with the same force value Figure $18(a, b)$ shows then changing of stent cells as well as the affected strut for both stent models (STENT I, STENT II) with both tension and compression loads. Under axial-tension loads, the behavior of the STENT I struts showed that the high-stress value near the vertex in the regions of the cell joint, as well as the cell junction, has been taken peak-to-peak end, and that could cause artery lesions or stent restenosis as well as stent fracture. While, in STENT II, the high-stress value appeared in the angle curve of the struts, however, the shape of the cell continues to expand in the same configuration (peak-to-peak). However, the total deformation at $5.5 \mathrm{~N}$ with STENT I beggar than STENT II by 17\%, as well as, the different of von-Mises stress values equal to $1.6 \%$ in-less with STENT II as illustrated in Figure 18 (a). In addition, under the axial-compression loads the struts behavior of STENT I have been bent with high-stress value at the strut that connected with links, and the cells compressed with different configurations that give a general understanding of reducing the artery lumen diameter invivo, that increased the probability of injury artery as well as a quicker stent fracture, while, in STENT II the struts almost impacted each other and the stress concentrated at the strut curve-link as shown in Figure 18 (b). Under axial-compression the results have been discussed in this work give a good agreement with the previous study [13] with gradual force loads. The gradual torsion load mode test was the second step of the mechanical comparison, Figure 18 (c), FPA torsion occurs in limb flexion [28], [10], the twist value is different in the popliteal artery than in the superficial artery in $13-20 \% / \mathrm{cm}$ and $26-43 \% / \mathrm{cm}$, respectively, in the gardening-sitting state as reported in previous works [28]. However, the moment type load applied to twist stent models gradually to observe the torsion effect on struts with two designs that provide a better understanding of the stent configuration in-vivo, the high-stress value of the STENT I struts observed in the strut arc curve, while in STENT II the high tension was concentrated in the middle of the arc link curve as shown in Figure 18 (c). During torsion, the change in the diameter of both models was monitored and more gaps in the dimensions of the stent model cells were taken, as well as the closed space in other cells, which could have affected the layers of the wall of the arteries, which leads to damage to the arteries, as well as, stent-buckling. 
STENT I
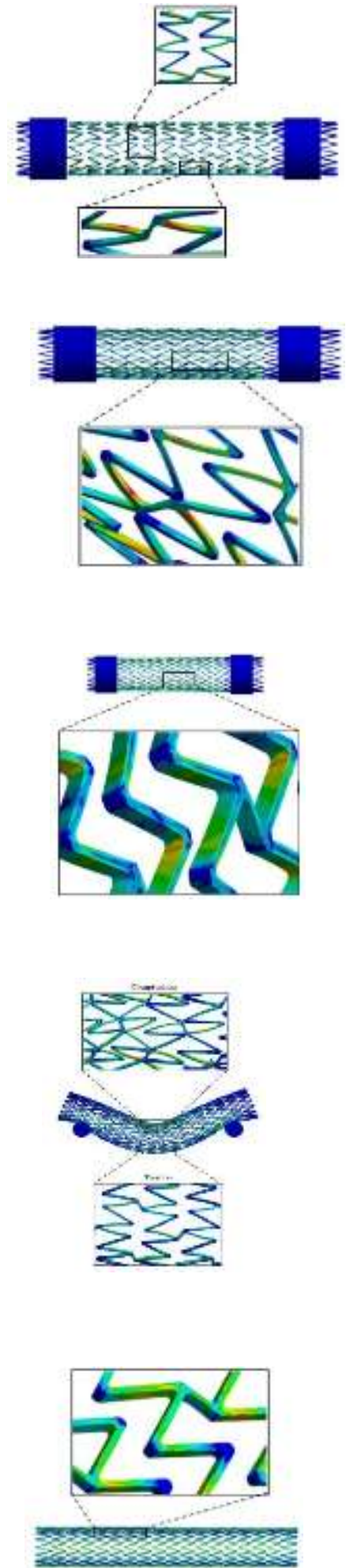

(a)

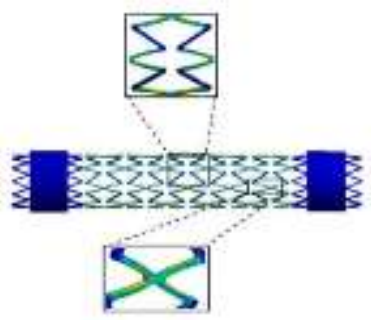

(b)

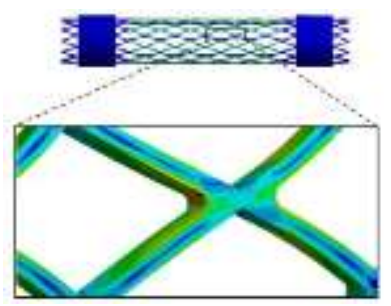

(c)

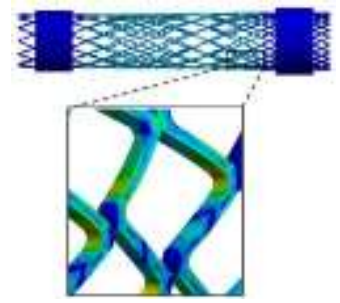

(d)

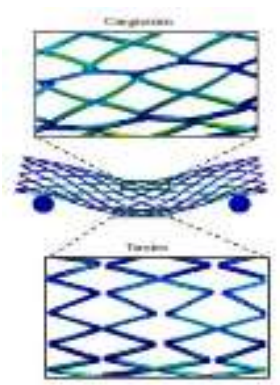

(e)

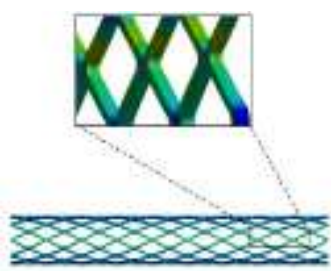

Fig. 18 - Von-Mises stress constriction with struts deformations for both models (STENT I, STENT II) under different loads: (a), (b) axial tension and compression; (c) torsion; (d) three-point bending; (e) radial compression

The third test mode was three-point bending, during this mode the response of stent models was better than axial compression that shows good agreement with recent experimental work [14]. Although the stent models (STENT I, STENT II) were bent during gradual loads, the cell of both models was deformed in varying ways, for example, the upper region of both models experienced compression while the lower part of both models was It acts as a tension region as illustrated in Figure 18 (d), it is a challenge to compare these results with recent works [14], due to the use of the displacement of the load pin as the application load. Nevertheless, the study showed a good agreement for the behavior 
of the stent during three-point bending with both models. The top compression region for both models gives a clear deform for stents in this area that most taken into account the reason that could injury that artery walls, as well as, the tension bottom area could rupture the artery layers.

The last test mode was radial compression, Figure 18 (e), the most desirable desired feature in particular with the height of the plugged lesion is radial compression. However, the high resistance force for STNET II than STENT I give a similarly good agreement with recent work [14], as well as, the resistance force approximately the same value compared to the previous work [14] in the S.M.A.R.T Control case $1.50 \mathrm{~N}$. Note that, the desire for a higher radial compression to keep the stent open against the collapse of the artery is necessary, but it is still unclear to measure how much is needed within the in-vivo with different stent lengths. The high-stress values were observed on the surfaces of the struts with the STENT I case, while in STENT II the stress values observed within the strut arc-curve. In addition, the over-sizing of the stent with high radial resistance may produce a chronic-outward-force that can injury the artery walls. For our knowledge up-to-date there is no clinically-research mention which of mechanical mode test is more important.

The limitations of this work come first and the most important thing that is sought in these test modes is that it does not cover the entire environment of the FPA configurations. As in the wall of the artery FPA, as well as the tissues around the stent could slightly be deformed in radial compression and other test modes. The second limitation must be taken into account in the fatigue life test and, in this work, only two common stent models were sought, so increasing the number of stent models could provide a better understanding of the vision. The last limitation is that FPA experienced combined mechanical loads at the same time, it should investigate what could happen with several combined loads instead of testing each mode alone.

\section{Conclusion}

The femoropopliteal artery stent models are necessary to deform variable modes of mechanical loads to keep the artery lumen open, therefore, the greater radial resistance with low axial compression, torsion and bending could be the characteristics required in FPA stents. FEM computational study was utilizing to predict the different of mechanical bench-top. A slight increase in total deformation was observed for both stent models under axial tension and compression, torsion, three-point bending, and radial compression. The similarity ratio of the total deformation in axial tension and the compression mode for STENT I and STENT II was 17\% and that may indicate that STENT I obtained a high deformation value instead of STENT II, while, the torsion similarity ratio was $86 \%$ which could show a good agreement in this mode, as well as the similarity ratio, was $78 \%$ of the total three-point bending deformation and the value of the similarity ratio in the radial compression mode was $23 \%$. This work provides a good understanding of the vision to monitor the unfolding deformation of the stent inside in-vivo, but it is still unclear what is the clinical mode of mechanical deformation that is more important than others with changing the length of the lesion and stent diameter, and the fatigue life test provides a better understanding of the mechanical tests that must be sought.

\section{Acknowledgement}

The authors would like to acknowledge the Air Conditioning and Refrigeration Techniques Engineering Department, Al-Mustaqbal University College, Babylon, Iraq, Faculty of Mechanical and Manufacturing Engineering Universiti Tun Hussein Onn Malaysia (UTHM) Parit Raja, Batu Pahat, Johor, Business Administration Department, AlMustaqbal University College, Babylon, Iraq and Engineering Technical College-Najaf, Al-Furat Al-Awsat Technical University, Najaf, Iraq.

\section{References}

[1] T. Inoue and K. Node, "Molecular Basis of Restenosis and Novel Issues of Drug-Eluting Stents," Japanese Circ. Soc., vol. 73, no. April, pp. 615-621, 2009.

[2] F. G. R. Fowkes et al., "Comparison of global estimates of prevalence and risk factors for peripheral artery disease in 2000 and 2010: A systematic review and analysis," Lancet, vol. 382, no. 9901, pp. 1329-1340, 2013.

[3] B. W. Nolan et al., "Prior failed ipsilateral percutaneous endovascular intervention in patients with critical limb ischemia predicts poor outcome after lower extremity bypass,” J. Vasc. Surg., vol. 54, no. 3, pp. 730-736, 2011. [4] S. H. Duda et al., "Sirolimus-eluting versus bare nitinol stent for obstructive superficial femoral artery disease: The SIROCCO II trial,” J. Vasc. Interv. Radiol., vol. 16, no. 3, pp. 331-338, 2005.

[5] O. Iida et al., "Cilostazol reduces angiographic restenosis after endovascular therapy for femoropopliteal lesions in the sufficient treatment of peripheral intervention by cilostazol study," Circulation, vol. 127, no. 23, pp. 2307$2315,2013$.

[6] J. Lubliner and F. Auricchio, "Generalized plasticity and shape-memory alloys,” Int. J. Solids Struct., vol. 33, no. 7, pp. 991-1003, 1996.

[7] F. Auricchio, A. Coda, A. Reali, and M. Urbano, "SMA numerical modeling versus experimental results: Parameter identification and model prediction capabilities," J. Mater. Eng. Perform., vol. 18, no. 5-6, pp. 649654, 2009. 
[8] F. Ansari, L. K. Pack, S. S. Brooks, and T. M. Morrison, "Design considerations for studies of the biomechanical environment of the femoropopliteal arteries,” J. Vasc. Surg., vol. 58, no. 3, pp. 804-813, 2013.

[9] W. Poulson, A. Kamenskiy, A. Seas, P. Deegan, C. Lomneth, and J. MacTaggart, "Limb flexion-induced axial compression and bending in human femoropopliteal artery segments," J. Vasc. Surg., vol. 67, no. 2, pp. 607-613, 2018.

[10] D. Scheinert et al., "Prevalence and clinical impact of stent fractures after femoropopliteal stenting," J. Am. Coll. Cardiol., vol. 45, no. 2, pp. 312-315, 2005.

[11] G. Nakazawa et al., "Incidence and Predictors of Drug-Eluting Stent Fracture in Human Coronary Artery. A Pathologic Analysis," J. Am. Coll. Cardiol., vol. 54, no. 21, pp. 1924-1931, 2009.

[12] A. Alqahtani, J. suwaidi, and M. Mohsen, "Stent fracture: How frequently is it recognized?," Hear. Views, vol. 14, no. 2, p. 72, 2013.

[13] I. W. L. Gore \& Associates, "Mechanical Properties of Nitinol Stents and Stent-grafts: Comparison of 6mm Diameter Devices," pp. 1-11, 2007.

[14] K. Maleckis et al., "Comparison of femoropopliteal artery stents under axial and radial compression, axial tension, bending, and torsion deformations,” J. Mech. Behav. Biomed. Mater., vol. 75, no. June, pp. 160-168, 2017.

[15] S. Müller-Hülsbeck, P. J. Schäfer, N. Charalambous, H. Yagi, M. Heller, and T. Jahnke, "Comparison of secondgeneration stents for application in the superficial femoral artery: An in vitro evaluation focusing on stent design," J. Endovasc. Ther., vol. 17, no. 6, pp. 767-776, 2010.

[16] Y. H. Lim and H. Y. Jeong, "Finite element analyses for improved design of peripheral stents," Comput. Methods Biomech. Biomed. Engin., vol. 20, no. 6, pp. 653-662, 2017.

[17] N. Eshghi, M. H. Hojjati, M. Imani, and A. M. Goudarzi, "Finite element analysis of mechanical behaviors of coronary stent," Procedia Eng., vol. 10, pp. 3056-3061, 2011.

[18] S. H. Park et al., "Efficacy of two different self-expanding nitinol stents for atherosclerotic femoropopliteal arterial disease (SENS-FP trial): Study protocol for a randomized controlled trial," Trials, vol. 15, no. 1, 2014.

[19] K. Maleckis et al., "Nitinol Stents in the Femoropopliteal Artery: A Mechanical Perspective on Material, Design, and Performance," Ann. Biomed. Eng., vol. 46, no. 5, pp. 684-704, 2018.

[20] B. Y. J. O. S. C. V. A. N. D. E. N. Berg and M. Lichtenberg, "How Self-Expanding Bare-Metal Stent Design Can Affect Procedural Results," vol. 6, no. 6, pp. 13-18, 2018.

[21] A. R. Pelton, J. DiCello, and S. Miyazaki, "Optimisation of processing and properties of medical grade Nitinol wire,” Minim. Invasive Ther. Allied Technol., vol. 9, no. 2, pp. 107-118, 2000.

[22] M. Conti et al., "Nitinol embolic protection filters: Design investigation by finite element analysis," J. Mater. Eng. Perform., vol. 18, no. 5-6, pp. 787-792, 2009.

[23] T. Nakayama, S. Jeong, S. Karkenahalli, and M. Ohta, “FEDSM-ICNMM2010-30592,” pp. 1-8, 2017.

[24] F. J. H. Gijsen et al., "Simulation of stent deployment in a realistic human coronary artery," Biomed. Eng. Online, vol. 7, pp. 1-11, 2008.

[25] R. Ní Ghriallais, K. Heraty, B. Smouse, M. Burke, P. Gilson, and M. Bruzzi, "Deformation of the Femoropopliteal Segment: Effect of Stent Length, Location, Flexibility, and Curvature,” J. Endovasc. Ther., vol. 23, no. 6, pp. 907-918, 2016.

[26] A. Kamenskiy et al., "In situ longitudinal pre-stretch in the human femoropopliteal artery," Acta Biomater., vol. 32, pp. 231-237, 2016.

[27] J. N. MacTaggart et al., "Three-dimensional bending, torsion and axial compression of the femoropopliteal artery during limb flexion,” J. Biomech., vol. 47, no. 10, pp. 2249-2256, 2014.

[28] A. Desyatova et al., "Limb flexion-induced twist and associated intramural stresses in the human femoropopliteal artery,” J. R. Soc. Interface, vol. 14, no. 128, 2017.

[29] Paisal, M.S.A., Taib, I., Ismail, A.E., Arifin, A.M.T., Darlis, N. An analysis of blood pressure waveform using windkessel model for normotensive and hypertensive conditions in carotid artery. Journal of Advanced Research in Fluid Mechanics and Thermal Sciences, Vol. 57, No. 1, pp. 69-85.

[30] Paisal, M.S.A., Taib, I., Ismail, A.E., Arifin, A.M.T. Numerical analysis on the effect of normotensive and hypertensive physiological conditions onto hemodynamic characteristics in stented carotid artery. International Journal of Mechanical and Mechatronics Engineering, Vol. 19, No. 1, pp. 94-107.

[31] Nemah, M.N., Low, C.Y., Aldulaymi, O.H., Ong, P., Ismail, A.E., Qasim, A.A. A review of non-invasive haptic feedback stimulation techniques for upper extremity prostheses. International Journal of Integrated Engineering, Vol. 11, No. 1, pp. 299-326.

[32] Paisal, M.S.A., Taib, I., Ismail, A.E., Arifin, A.M.T., Mahmod, M.F. Evaluation system on haemodynamic parameters for stented carotid artery: Stent pictorial selection method. International Journal of Integrated Engineering, Vol. 11, No. 1, pp. 225-246. 